\title{
Towards Innovative Humanities: The Text as a Laboratory. Traditions, Hypotheses, Ideas
}

Ryszard Nycz 
Ryszard Nycz

\section{Towards Innovative Humanities: \\ The Text as a Laboratory. Traditions, Hypotheses, Ideas}

DOI: 10.18318/td.2015.en.1.3

\section{Preliminary Remarks}

I am formulating these remarks convinced about the need for the development of an operative theory of the text in the humanities, one grounded in my experience in Polish Studies (i.e. the study of Polish literature and discourse of the local cultural environment) but inspired by the international state of research and leading to more universal consequences, related to the place and role of the humanistic text as well as the need for the new theoretical conceptualization. The latter is meant to, among others, produce a tool enabling a transfer (and the necessary remaking) of the indigenous goals and challenges of humanistic studies to the environment of contemporary scholarship and cyberculture.

Such an approach to these central issues may seem an anachronistic attempt to go back to the so-called textual turn in the humanities, especially today, when linguisticautonomist methodological assumptions are abandoned in search of tools that can provide access to the possibly direct, empirical, as well as cognitive and practical dimension of the object of the human studies. I do not believe, however, that such a goal may be achieved without a critical analysis of the text's status in the humanities so far, nor without a consideration of the possibility of its
Ryszard Nycz professor, director of the Department of Anthropology of Literature and Cultural Studies at the Jagiellonian University, an employee of IBL PAN. Editor-in-chief of Teksty Drugie. Corresponding member of the PAN and PAU, KNoL PAN and KNoK PAN. President of the Editorial Committee of the series"Nowa Humanistyka." His recently published work is Poetyka doświadczenia. Teoria

- nowoczesność

- literatura (2012).

Contact: ryszard. nycz@uj.edu.pl 
reworking. I also do not believe that it is possible, or worthwhile, to reject the "texto-centric" specificity of not only literary or linguistic research but also of the humanities as a whole (although in the case of the latter, to a varying degree).

Incidentally, we are currently witnessing not a decrease but a profusion of textual practices, new genres, styles and textual conventions, as well as techniques of their analysis and processing - in the private and public spaces, old and (particularly) new media. This does not mean, naturally, that texts have remained the key object of research; in contemporary visual culture or in cyberculture they function as equal to research objects of different types, or are part of hybrid multimedia constructs (alongside pictures, photographs, films, animations, artwork etc.) In each of these cases, however, texts remain inherent components of the contemporary cultural reality, and the method of "reading culture" modeled upon them has retained the status of a cognitively privileged tool of analysis and interpretation.

The crux of the problem lies, I think, in the fact that the text (and, through a metonymical relation, text-oriented program of research) is viewed today as both the source of marginalization of the humanities (in the eyes of its critics) and as the refuge for their non-obsolete value (in the eyes of the majority of its defenders). At the same time, in both cases we are dealing with a very particular, modern concept of text as an autonomous, finite product of sense-making human activity - one of many possible concepts, and an insufficiently supported one.

As we know, the contemporary debate on scholarship and academic policy conducted from the perspective of the so-called "techno-university" (the current model of research and education, see: Bińczyk) lead to the growing marginalization of the humanities deemed as a knowledge only somewhat (or even completely un-) usable since they result neither in innovation nor in real influence (effecting change) in the cognitive, social, political or cultural sphere. Such a critical evaluation is usually based on the premise that research in the humanities focuses solely on the text understood in the traditional manner as something objective and autonomous (in relation to the social and "practical" realities). One must, I believe, agree with the formal categorization of the specificity of research in the humanities (but not with its content and assessment). The text, in its broad cultural sense and myriad shapes and functions, indeed continues to remain the common object, center and research result of the disciplines within the human studies.

I propose to acknowledge the text (textuality, discursiveness) as the shared foundation and object of the humanities. I also believe that its understanding must be modified. A humanistic text is not only a standard object and should not be treated as such; it should not be treated as a neutral vehicle for finite 
results of cognitive and creative work carried out elsewhere and at a different time; a re-presentation of something preexistent and independent. The text is also a process, accumulating within itself (and regulated by professional procedures), of creation, cognition, investigation, including also the technicaldisciplinary, cultural and experience-based environment activated as a result of the process that, and following Latour, is "the functional equivalent of a laboratory. It is a place for trials, experiments and simulations". Only when those three dimensions are considered together, we may learn, as I think, the nature of our "discoursive" object.

A preliminary outline of an operational theory of the humanistic text which is proposed here is neither aimed to fortify the barricades surrounding the humanities' traditional "autotelic" model of research and education, nor to subordinate itself to the criteria of strict sciences (for instance, by attempting to show that it respects their standards). Instead, it is meant as a positive response to a contemporary problem and an attempt to provide a remedy for the crisis of the disciplinary identity - leading to a rethinking and remaking of the identity of the humanities as a result of their critical confrontation as much with their own tradition as with the criteria, standards, tasks and goals of contemporary scholarship. Taking into account this strategic goal, I will be consciously using the following terms: "innovation" - used to denote "science" in the jargon of the education administrators; "humanities" (including also Polish Studies) - with a modified formula of disciplinary identity; finally, the metaphorical description of "text as a laboratory" borrowed from Bruno Latour as a figurative premise of the following argumentation.

\section{Three Models of Academic Research and Education, Their Defenders and Dysfunctions}

The reflection on the history of the humanities and the ideas associated with their practice within the institution of university in the West which was recently expressed to such a fervent extent (see: Bloom, Culler, Gumbrecht, LaCapra, Nussbaum, Readings, Said; also in Poland: Domańska, Kozielecki, Markowski, Rewers, Sławek, Zeidler-Janiszewska and Czerepaniak-Walczak), enables us to identify and present, in a necessarily simplified manner, three basic models of academic research and education, each exhibiting a decidedly different focus with regard to their underlying assumptions, goals and the means to achieve them.

The first model may be labeled for m a tive. It centers primarily on the subject - not only its education but also formation (and it dates from the antiquity until the beginning of the 2oth century). This was the goal of the ancient studia liberalia and the modern studia humanitatis, of the Kantian 
"university of reason", that assumed the formation of the individual based on the Enlightenment model of universal humanity, and later of the Humboldtian "university of culture", aiming to educate the citizens not only into learned people but also ones imbued with the spirit of national culture. In this model, high standards of "personal" culture were the goal (or "attribute", to use S. Pietraszka's term) of university education and they manifested themselves via the reproduction of the man of culture (the nation's elite). This formative model, aimed to shape the subject, became gradually replaced from end of the 19th century by the subsequent one.

The second model - the profes si o nal one - concentrated on the study of the object and on teaching the competence of its humanistic cognition (from the second half of the 19th century until the second half of the 2oth century, and in Poland - until the present day), for in this model, the culture, its products and processes have become an autonomous object of research equal to all others. The process was parallel to the establishment of Geisteswissenschaften (human sciences, cultural sciences) in the day of the so-called "anti-positivist turn". This lead to a professionalization and division of humanistic knowledge into disciplines that later further divided into separate, isolated sectors of scholarship, a consequence of the fact that their autonomous identities were legitimized by their ability to prove the existence of a separate object and method of study. Culture became one of such objects, and within it the text - as a material-semantic device used to contain, store, transfer and convey meanings, while expert analytical knowledge transformed into a specialized methodology of identifying, expressing and explaining the authentic (and fundamentally unchangeable) meaning of the message.

I propose to call the third model in novative, as it places the greatest emphasis on technique (in the source sense of techne as a method of discovery), consequently, on discoveries (in the basic sciences) and inventions (in applied sciences) - at the cost of basic research (since the 6os, dominant today). It is also referred to as the "market" university model (for the market dictates research preferences and establishes funding priorities) or as the "university of excellence" (as it introduces a universal system of evaluation and competition with the use of homogenizing quantitative criteria). The "techno-university" would be, perhaps, the most fitting name for this model, as it promotes techno-scholarship, in other words, striving toward innovation. Generally speaking, it seeks a constant improvement of methods and techniques of data processing and a production of results of practical, social and civilizational importance.

Within the scope of this model, human studies have apparently found themselves in a stalemate: it was stated that these studies were devoid of techno-innovative potential, pushed to the margin, tolerated with increasing 
reluctance by the administrators of science. One should add, however, that while a similar stalemate affects both the traditional and modern humanities, this cannot be said of its two new varieties. On the one hand there are the c o g nitive humanities (sometimes also called neuro-humanities or new humanities), searching for techniques and methods of access to the pre-discoursive and pre-conceptual activity of the embodied mind as the source of human creation and culture (Gottschall, Singerland, Wilson); on the other hand, there are the digital humanities where precisely the technique or craft, i.e. digital technology, become the hotbed and the source of changes bearing widespread (although, so far, rather proclaimed than proven) practical, methodological, epistemological and ontological consequences (Burdick, McGann, Presner).

Although those different emphases of university research and education models could constitute complementary dimensions of acquiring education and the practice of scholarship, their history indicates that they are competitive and center on seemingly incompatible goals. The forming of the subject, the study of the object, technical efficiency (and agency) in the sphere of broadly understood practices and processes of mediation are all diverse (although deeply connected) types of activity. All seem equally important, both historically and today, however, they have always been mutually hierarchized; throughout the history of science, evolution of knowledge models assigned primacy to the newer ones.

The defenders of the value and social importance of the contemporary humanities position themselves - which is symptomatic - within the range of the above-mentioned models. Some view the humanities as, primarily, the last and irreplaceable locus for the shaping of individuals - their culture, self-knowledge, identity - into insightful, critical, open, creative citizens and members of community and society (Bloom, Gadamer, Nussbaum, Readings). Others hold it to be, first and foremost, a place to develop, implement and spread professional knowledge about human sense-making activity and its creations. It is a knowledge subordinated to the rules of disciplinary specializations, as well as strict standards of verification and falsification; knowledge of permanent value whose acquisition ensures also the possession of autonomous professional competences (Fish, Gumbrecht, Said, Waters). Others yet, (whose numbers are still low but growing) see it as a place of the return of the repressed. I am talking here, naturally, about technique (techne): once located at the heart of the Platonic myth of culture's creation (in Protagoras), a divine art stolen by Prometheus, later held to be the opposite of culture - that returns today as the most important ally of the evolving humanities in their struggle for survival in the contemporary horizon of knowledge and media environment (Stiegler, Hayles, Debray, Berry). 
The strength of the first model, focused on the formation of the subject, was also recognized relatively early as the source of its weakness. As Jonathan Culler notes, if the goal of the university is to develop a man of culture, then the man of culture would be instantiated in the professor. Hence the popularity of anecdotes such as that of "a dowager accosting an Oxford don during World War I: 'Young man, why aren't you in France, fighting to defend the civilization. 'Madame', came the reply, 'I am the civilization they are fighting to defend"1. Therefore the point is that in the eyes of the common man, the autotelic model of education not only reproduces social inequality but also, first and foremost, promotes the production of "asocial" individuals with a sense of entitlement; disinterested as they have no interest to engage in the needs or subordinate to the imperatives of the collective.

The advantages and disadvantages of the second model, where culture (and by extension, a text) become the object of research, similarly to the third model, where culture and technology shape the media space and govern the processes of mediation (and the media are not simply a carrier of the message, having a significant impact on our relation with the world), are broadly discussed today. I would like to mention just one aspect of the issue: that of the innovative character of textual research and text-producing scholarship, conceptualized not directly (which, as we know, is a difficult matter, if at all possible) but via negativa, as surely it is a little easier to say what innovation is not than what it is... I believe, although I am relying for now on my own observations and hypotheses, that among the most widespread research practices that are likely to be deemed as legitimate, even to a certain extent valuable, though definitely not innovative, one will find the following five trends:

1. the reproduction or ordering of the cognitive results of others (instead of arriving at one's own);

2. proclaiming one's own position (without sufficient supporting argumentation or outlining its connection to the contemporary state of knowledge);

3. concentration on methodology and perfecting one's craft (without acknowledging the need for its verification or its usefulness with regard to the empirical material);

4. extensive practice of disciplinary scholarship based on filling "gaps" (concerning a previously overlooked object or features of the already known object) by applying a routine research procedure;

5. concentration on solving only elements of research problems or perceived problems (while omitting fundamental issues).

1 Jonathan Culler, The Literary in Theory (Stanford: Stanford University Press, 2006), 249. 
If the above observation is correct (or at least worth consideration), two conclusions may be drawn. Firstly, non-innovative practices characterize a large share of research in the humanities (including, surely, also the Polish humanities). Secondly, innovative practice - defined tentatively as a symmetrical opposite of the above-mentioned trends - would involve a preference for: transdisciplinary research with a clear empirical footing (appropriate for the discipline), closely tied to a new theoretical conceptualization (one well rooted in the state of research) and leading to a formulation (or a re-interpretation, or solution) of a problem of fundamental importance to a given discipline, and (by extension) to the entire discipline of knowledge. But this characterization, although it identifies important conditions for the emergence of innovation within the humanities, still fails to capture their specificity.

\section{The Specificity of the Humanities, or on the Three Meanings of Stefan Czar- nowski's One Sentence}

One could, naturally, elaborate endlessly on the specificity of the humanities, but in the following paragraphs and with the help of just one example, I would like to identify its three crucial and rather generally accepted meanings. A renowned Polish sociologist, religion scholar and cultural anthropologist, Stefan Czarnowski closed the preface to his last, posthumously published book (Culture, 1938) with the following simple sentence: "Because the study of culture also is culture". Naturally, one may reflect on it in the context of the entire preface, especially its connection to the preceding sentence that includes a conventional invocation to the reader: "It is up to the readers to decide about the extent of the result of our attempts has enriched culture"2. Interpreted within this frame, the last sentence is a kind of rhetorical finish for the preceding appeal to the readers, an ornament, additional decorative expression that adds nothing new, closing the argument with a general reflection. However, the logic of supplementation (as we have learned from contemporary philosophers and theoreticians) is governed by its own laws, and when it is applied, that which looks to be a simple ornament may fundamentally change the surface meaning.

Firstly, let us note that the proposition contains a clear d e m a r c a ti o n. This becomes very apparent when we realize that the study of nature (one should add: by following standard practices and approaches of nature scientists) is not a part of nature. The study of culture, on the other hand, is a part

2 Stefan Czarnowski, Kultura. Dzieła T.I: Studia z historii kultury, ed. N. Assordobaj, S. Ossowski (Warszawa: PWN, 1956), 23. 
of culture - and this is one of the features that clearly differentiates this type of studies from the so-called strict sciences; the study referred to as Geisteswissenschaften, cultural studies or simply humanities. The former deal with things that simply are, the latter with things that carry meaning. A more recent tradition allowing to capture the consequences of this distinction is rooted in the so-called anti-positivist turn that brought about the emergence of the humanities; a more distant one develops from the ancient and modern reflection on the "growing" of meaning and its effects in form of products of culture.

If the first context pointed to the differentiating and identity-related sense of the proposition, the following one reveals an internal diversification of the field of knowledge in question. If "the study of culture also is culture" then there must be an underlying assumption that study as such is not culture (in the narrower sense) and culture is not studying (understood more strictly). However, both are interconnected and influence each other within the framework of a broader or more special notion of culture. One can see here a division into cultural creation (products of culture) and the knowledge or processes of cultural study. It is a division that today resurfaces in the form of a dualistic concept of culture, described on the one hand phenomenalistically (culture as a system of products and practices that result in them), and on the other hand, idealistically (culture as a system of meanings and symbols, patterns, an axiological-categorical network). Culture certainly is both - that which we see and that through which we see - but the debates among philosophers and theoreticians of culture show that it is difficult to combine these two approaches or to unite them under some sort of a broader category.

An analysis of the above sentence in a yet different light allows to enrich its characterization and to see in it an expression of an even more pronounced position than the descriptive-typological perspective. "The study of culture is also culture" also means that the knowledge of the object and the means to achieve it become a part (an aspect, a dimension) of the studied object. Cultural creation includes a cognitive dimension, and cultural study - a creative component, as it "forms" or "enriches", and consequently changes (at least to some degree or extent) the studied object. And this new object must demand a new cognitive operation, which turns the process into a never-ending, everlasting endeavor. Generally speaking, it is a process in which what men do in their cultural environment refers both to the objects and to men themselves and through that feedback, their self-knowledge and the described states of things are modified and acquire new depth. And if so, then one could also say that the most characteristic feature of inventive study in the humanities is the fact that it forms or co-shapes (consequently, changes) that which it refers to (which, by the way, connects cultural texts of this kind to the records of pre-conceptual states of the primary level, of similar 
properties; to the attempts at a discoursivization of the "primary experience" or the "emotives" - see: Petitmengin, Reddy).

I have attempted to extract from Czarnecki's seemingly purely rhetorical formulation three meanings of culture. The first one separates and differentiates the study of culture (the humanities) from natural (strict) sciences, endowing it with a relative identity. The second one indicates an important internal diversification within this field of knowledge, stretched between alternative (and frequently competitive) approaches: one that defines culture as a network of patterns and symbols, and the other that views it as a system of practices and products. The third meaning highlights the mutual influence of the idealistic and phenomenalistic dimensions, rooted in the reflexive, reflective character of research within the humanities. And if its cardinal feature is the fact that it forms (changes) that which it refers to, it also has an importantly innovative or creative - or, to use a more appropriate word, inventive - character.

It is, however, a clearly different type of innovation. At a risk of a far-reaching simplification, one could say that discoveries in basic sciences change (multiply) our knowledge, not the world. Inventions, on the other hand, enrich (change) the "furnishings" of the world (and of man) adding technical artifacts and ways to manage its resources or properties, and their productive use and processing. Meanwhile, successful inventions proper to the humanities penetrate, to an extent, both of these spheres: through their creative practices (techne - ars) they produce artifacts constituting media for cultural senses that provide access to overlooked features or aspects of the world of human experience; and this way, while creating - they make discoveries.

Relating the discussed models of knowledge and properties of humanist cognition to the textual research and practices, one notices that each of them results in the different profiling of the latter. In the traditional model of the humanities, centered upon the forming/educating the subject, classical texts appeared in a de-contextualized (and frequently fragmentary) form and were treated, first and foremost, as reservoirs of conceptualizations of universal issues allowing to penetrate key philosophical, moral, social or political problems. Commenting on Durkheim's observations on the matter, Pierre Bourdieu notes that throughout the 19th century, as a result of a merge between the universalist humanism and "a reading which is attentive solely to the properties of form" 3 there emerges an autonomous field of humanist knowledge where this model begins to surrender to the subsequent one, centered upon creation, reading and study of texts as an autotelic object:

3 Pierre Bourdieu, The Rules of Art. Genesis and Structure of Literary Field, trans. Susan Emanuel (Stanford: Stanford University Press, 1995), 301. 
Pure production produces and presupposes pure reading, and ready-mades are just a sort of an extreme case of all works produced for commentary and by commentary. To the extent that the field gains autonomy, writers feel themselves increasingly authorized to write works destined to be decoded, hence subject to repeated reading necessary to explore, without exhausting it, the intrinsic polysemy of the work ${ }^{4}$.

The same process is described from a different perspective by David Olson. Olson believes that The World on Paper of the literacy era, and then of print era, becomes gradually de-empiricized by eliminating all non-textual factors that condition the sending and receiving of sense (such as the author's intention, the situation of utterance, contextual relations, anchoring in experienced reality). This results in an autonomous reality of the text with a self-sufficient meaning, the text is a kind of a container used to store, convey and share (with all who can read) the intact deposit of sense. According to Olson, this is how a modern, autonomous text provides not only a model for speech but also for the constituting of the modern, autonomous subject ${ }^{5}$. One could take this a step further; in its extreme form, such a concept of the text (seen as a field or network of meaningful elements), textual writing and print are no longer technical devices but become what Lewis Mumford calls a m a chin e: an autonomous order of functions, a device to annihilate time and space, a process separate from objects or substances (although embodied in an artificial device) ${ }^{6}$. In contemporary virtual space, this process has surely only intensified and taken new forms.

Latour's formulation of "text as a laboratory" may appear as a risky and inadequate metaphor for the specific practices (and their conceptualizations) within the humanities, which is perhaps why Łukasz Afeltowicz judged it to be of little use to describe them? ${ }^{7}$ I must disagree. If Latour's formulation is to be treated as a metaphor of an "isolated closed system" (the basic methodological procedure in natural sciences) that the humanities develop using their own means, then the modern model of an autonomous text fulfills - wishes to fulfill - the criteria of modern science. The "device"

Bourdieu, The Rules of Art, 305.

5 David R. Olson, The World on Paper: The Conceptual and Cognitive Implications of Writing and Reading (Cambridge: Cambridge University Press, 1996).

Lewis Mumford, Technics and Civilization (Chicago: University of Chicago Press, 2010). Łukasz Afeltowicz Modele, artefakty, kolektywy. Praktyka badawcza w perspektywie współczesnych studiów nad naukq (Toruń: Wydawnictwo Naukowe, 2012). 
of the autonomous text: (a) reduces the complexity of the object's features (by isolating them from the conditions of their emergence, intentions of the subject, contextual, historical and social meanings as well as the non-textual environment and experience of the receiver); (b) assumes a systematic standardized analytical procedure (rules for a competent, professional interpretation); (c) produced repeatable results ("correct" interpretation of the work's meaning); (d) results agreed upon and legitimized by the "interpretative community" (a certain equivalent of the criterion of teamwork in strict sciences, although the tendency for teamwork has become noticeable also in the humanities).

According to the ethnologists of science, the difference between what sciences proclaim within the standard theory and what they actually do in the laboratory also characterizes the relation between this modern ideology of the text and the actual textual practices among the humanists. The contemporary view of the textual laboratory (in the general and more tangible sense: a library, archive, workshop...) - and here I am about to point to the status of the text in the third, innovative or technical model - does not rely on the idea of autonomy, nor on the notion of the text as a container, but rather sees the text as a nexus of relation networks that penetrate and shape the historical, social and cultural environment. The intention remains a crucial element of meaning, just as the situation of the utterance (both created by the text and represented by it), and the contextual relations, tested through the process of reading that cannot succeed without a significant engagement of the experience and knowledge of the receiver. The meaning is not a "ready" datum represented by the text but a relational feature written onto the technical (textual) instruments of cognition and mediation, through them forming and sharing its shape.

In fact, this concept of meaning is nothing exceptional; it is broadly accepted, among others, among cognitive linguists. According to Gilles Fauconnier, for instance, linguistic expressions have no stable, ready meaning, instead they are a kind of instruction with a potentiality of meaning actualized and concretized as the discourse develops and is understood through the attempts (acts) of placing it within the frame of contexts and discursive as well as non-discursive environment constructing the network of "mental spaces" where the meaning of the message is located and developed ${ }^{8}$. However, in her description of the literary text, conducted from the perspective of critical discourse analysis, Dominique Maingueneau says that to see the literary text as discourse means:

8 Agnieszka Libura (ed.) Amalgamaty kognitywne w sztuce (Kraków: Universitas, 2007). 
to reject the fantasy of the work in itself, in the double sense of a work of autarchy and a work from the depths of creative awareness; to return the work to all spaces that make it possible, spaces where it is produced, evaluated and where it is managed. The conditions of speaking permeate that which is said, and that which is said relates to its conditions of being said (the status of the writer connected to the ways he or she is located within the field of literature, the functions ascribed to genres, the relations to the receiver created by the work, material medium and the methods of circulation of the utterance). [...] The context is not located outside the work like subsequent layers of the work, the text itself governs its context. Yes, texts speak about the world but the acts of their utterance partake in the world they are meant to represent. We do not have a universe of silent objects and actions on the one hand and on the other, with separate representations meant to portray them. Literature is also an act; it not only speaks about the world but also organizes its own presence in this world?.

\section{Three Types of Textual Practices in the Humanities}

Work on texts, a crowning discipline of not only literary studies, means working with texts and "using texts" (or "through texts"). The latter is of paramount importance and, in my opinion, specific to the humanities because it complements the former but also absorbs and transforms them. In the humanities, the text is more than an object or partner, it is first and foremost a guide: more than a medium or transmitter - a mediator that, positioned in between, somehow also produces that which it mediates (Debray); it shows the direction and paves the way; finally, it serves as a kind of Baedeker through the newly discovered routes and tracts of experience. It is a guide leading to an understanding of the other, provided that at the same time it allows, as Bakhtin suggests, for an understanding of itself as the other.

Extrapolating these remarks onto the territory of poetics, one could say (with a necessary simplification) that each of these types of interest in the text will profile differently the tasks of the poetics of the text in the humanities (and, by extension, of the literary and artistic text):

1. the model of working with texts - rooted in the spiritualhermeneutic tradition (as well as its theological branches) where the text (work of art) acquires the features of the subject; it asks questions

9 Dominique Maingueneau, Le Discours litteraire. Paratopie et scence d'enunciation (Paris: Armand Colin, 2004). Based on the Polish translation by $\mathrm{H}$. Koniecka prepared for print in the Horyzonty nowoczesności series and used by R. Nycz. (AW) 
or provides answers, looks at us (but at the same time, according to Benjamin, draws attention and enforces auratic distance), it is a maker, it exerts influence etc. The text is the Other that we encounter, a partner in a conversation through which it opens itself to our understanding, submits to interpretation and presents (represents) that which on "the other side" is to an extent potentially already given, worked out and deposed in the work: the spiritual world of the author and the historical sense of the work.

2. the model of working on texts that focuses primarily on the study of the text (work of art) as an artistic object - closed, formally finite and separate (autonomous) - and aims to capture the rules of its internal organization, the deeper order of its sense, which is a distictive feature of the entire philological-structuralist tradition, classical editing as well as archival and source studies, etc.

3. the model of "using texts" which activates and emphasizes another aspect of the heritage of poetics; one where poetics is first and foremost a technique (in a diversity of its historical senses, however, centered upon the cardinal one, as a method of discovery). From technaksein kai theorein ("inventive thinking" - so that something may be created out of things that may be or not be, following Aristotle) and the art of inventive search for the "missing word" (Steiner) to Bakhtin's notion of "exotopic" poetics (based on the premise of necessary temporal, spatial and cultural distance between that which is comprehended and the comprehending agent) and Adorno's concept of the text as an idiosyncratic procedure of finding networks of linguisticconceptual relations where things form their shape available to human cognition.

I have listed these rather commonsensical and tentative models of textual practices performed within the contemporary textual laboratory of the humanities also in order to highlight different directions of the possibilities of inventive (innovative) acts. In the first model, the text is a kind of a partner (assistant, tool) in solving a task or issue different from the one that provoked the text; features of the text become analytical categories providing access to phenomena or problems of non-textual nature. In the second model, the text becomes an object of analytical, experimental inquisitiveness by the way of which a change of questions posed to the text, the conceptual network where it is located, the experienced frames of reading, results in different answers, activates dimensions of sense that had been hidden so far, reveals the repressed of unconscious layers of the record of experience. 
In the third model the text is conceived primarily as an inscription of the process of its development and a simultaneous construction of meaning. The questions of producing knowledge (generally speaking), and particularly the traditional question of creative process, destined (or so it would seem) to be forgotten or disregarded (as it takes form of non-scientific deliberation) must undoubtedly claim its rightful place as a part of the humanist reflection, especially as it has already regained its academic status in cognitive neurophenomenology.

This can be seen for instance in the work of Claire Petitmengin who in her analyses of first-person testimonies of the creative process (by scientists, philosophers, artists, writers) managed to reconstruct the main stages of constituting, profiling, negotiating and narrowing down of sense in the process of developing texts: from "source thoughts", a residual, pre-conceptual and pre-discursive fermentation threshold of the semantic amalgam in the form of multi-sensorial and transmodal "felt meaning" of the experience to a conceptually and discursively formatted meaning that, nonetheless, does not repress the residual stage but, on the contrary, can be properly read only in relation to it and from it draws its energy (intensive stimulation) for further transformations.

This invention of sense, captured in the textual "experiential protocols", allows to uphold a:

dynamic, enactive view according to which cognition, far from being the representation of a pre-given world, is a process of co-construction of the inside and the outside, the knower and the known, the mind and the world [...] If our ideas draw their meanings from the preverbal dimension of our experience, then there is no real understanding which does not attain such depth. Understanding an idea means accessing the felt meaning which is at its source, thanks to specific gestures ${ }^{\mathbf{1 0}}$.

But the point here is also about sanctioning the value of more pragmatically and practically oriented research leading to an analytical and theoretical reflection on the techniques (patterns, procedures) of creation/construction of the text in humanities. Because a developed inventive text partakes in the solving of the problem, becomes the operator of reorganization - attuning all elements of the research procedure and integrating them into parts of a methodically constructed discourse. A development of an effectively organized analytical text (of one's own) also activates the network of meaningful

10 Claire Petitmengin, "Towards the Source of Thoughts. The Gestural and Transmodal Dimension of Lived Experience", Journal of Consciousness Studies, 14, No. 3 (2007): 77 and 79. 
relations between the elements of the studied text and allows to develop systems (regularities, orders) thanks to which the text gains a place and meaning in culture, while the researcher - a new form of sharing also their s own experience.

Emphasis on the development and research of techniques, or even technologies, of producing texts, processing data, logistics of transmission and managing reception grows significantly in the field of the new, digital humanities perhaps highlighting at the same time its central interest. This is how Schnapp and Presner describe this evolution in their manifesto:

Like all media revolutions, the first wave of the digital revolution looked backward as it moved forward. Just as early codices mirrored oratorical practices, print initially mirrored the practices of high medieval manuscript culture, and film mirrored the techniques of theater, the digital first wave replicated the world of scholarly communications that print gradually codified over the course of five centuries: a world where textuality was primary and visuality and sound were secondary (and subordinated to text), even as it vastly accelerated the search and retrieval of documents, enhanced access, and altered mental habits. Now it must shape a future in which the medium specific features of digital technologies become its core and in which print is absorbed into new hybrid modes of communication.

The first wave of digital humanities work was quantitative, mobilizing the search and retrieval powers of the database, automating corpus linguistics, stacking hypercards into critical arrays. The second wave is qualitative, interpretive, experiential, emotive, gene rative in character. It harnesses digital toolkits in the service of the Humanities' core methodological strengths: attention to complexity, medium specificity, historical context, analytical depth, critique and interpretation"1.

I have cited these two examples of "using text", of interest in the processes of the creation of texts and the production of knowledge also because they reveal two key liminal areas or, perhaps, posthumanist wings, between which contemporary humanities have found themselves: neuroscience - reaching into the pre-conceptual and pre-linguistic, corporeally experienced level of communication that connects the human being to all other beings, and digital technology - that signals the "computational turn" in the developing

11 Jeffrey Schnapp, and Todd Presner, "The Digital Humanities Manifesto 2". http://jeffreyschnapp.com/wp-content/uploads/2011/10/Manifesto_V2.pdf 
"machine-centered" and "postperceptional" (since it is disembodied) cyberculture. It will depend on the elasticity and strength of contemporary humanities if they are going to be absorbed by those two, becoming a component of other fields of knowledge (perhaps even an important one, but one without the right to autonomous existence) or if the humanities attempt to absorb and use them for their own purposes, re-defining their identity and right to exist among the fields of contemporary science and "technoculture". A third option - a return to the old status quo - is probably (no longer) possible.

\section{Conclusions}

I propose to abandon the modern ideology of text as a container, separated from the world, an autonomous laboratory of standard procedures of representation, preservation, transmission and reception of meaning. I also propose a move toward a contemporary (and Latourian in spirit) notion of the text's laboratory as a nexus of open network of translational operations between the natural, social, discursive, mediatory and inventively transforming the relations between the mind, the body and the environment. This operational concept of the cultural text combines the knowledge of strictly disciplinary character (knowing that) with the causative knowledge (knowing how) and is of mediatory nature, conciliating between oppositional models of knowledge and types of textual practices; it allows a transition from modern to new humanities (posthumanities? neurohumanities? digital humanities?) that today search for a place between the empirical and the virtual.

In a text constituting a locus classicus for the traditional education in humanities, Seneca the Younger encourages a young student to abandon blind obedience to the authority of "great books":

"This is what Zeno said". But what have you yourself said? "This is the opinion of Cleanthes". But what is your own opinion? How long shall you march under another man's orders? Take command, and utter some word which posterity will remember. [...] But it is one thing to remember, another to know. Remembering is merely safeguarding something entrusted to the memory; knowing, however, means making everything your own; it means not depending upon the copy and not all the time glancing back at the master. "Thus said Zeno, thus said Cleanthes, indeed!" Let there be a difference between yourself and your book!12

12 Seneca, Epistles, Volume I. (A Loeb Classical Library: 1917) trans. Richard M. Gummere. https:// en.wikisource.org/wiki/Moral_letters_to_Lucilius 
Although we are decidedly more skeptical today about the neutrality and effectiveness of memory techniques (remembering things as they really were), Seneca's key postulate - that doing is the ultimate test of knowing, about the primacy of "knowing how" over "knowing about" - still remains true. Two millennia later Humberto Maturana and Francisco Varela coined from this postulate - in their formulation stating that all doing is knowing and all knowing is doing - the credo of the new, united and holistic concept of the mind, matter and life ${ }^{\mathbf{1 3}}$.

Transforming the humanist knowledge into a tool of causative action, successful change, effective influence, continues to remain a challenge for the humanities, more pertinent today than it possibly ever was. Perhaps we may approach this goal by reminding ourselves of the traditions of operational treatment of texts, by making an attempt at an operational reformulation of their concept and by striving to design research and education programs adjusted to the environment of the humanities of the future. The environment and the humanities that we already find ourselves in, that, after all, surround us already.

Translation: Anna Warso

13 Humberto R. Maturana and Francisco J. Varela, The Tree of Knowledge. The Biological Roots of Human Education (Boston-London: Shambala Publications, 1998), 26. 